\title{
Accuracy of Borg's ratings of perceived exertion in the prediction of heart rates during pregnancy
}

\author{
M. E. O’Neill FRACP, K. A. Cooper BSc (Hons)*, C. M. Mills Teaching Certt, E. S. Boyce \\ FRACOG‡ and S. N. Hunyor FRACP \\ Cardiovascular Research Unit, Department of Cardiology, Royal North Shore Hospital, Sydney, Australia, \\ *Australian Catholic University, North Sydney, Australia, +Les Mills' World of Fitness, Auckland, New Zealand, \\ ‡Department of Obstetrics and Gynecology, Royal North Shore Hospital, Sydney, Australia
}

When using Borg's 6-20 scale during pregnancy, ratings of perceived exertion (RPE) did not significantly correlate with exercise heart rates (HR) $(P>0.05)$. The $H R$ predicted from RPE significantly $(P<0.05)$ underestimated the exercise $H R$ in the second trimester during walking (Group 1: mean difference 16 beats $\min ^{-1}, n=11$ ), aerobics classes (Group 4: mean 15 beats $\min ^{-1}, n=48$ ) and circuit training (Group 3: mean 18 beats $\min ^{-1}, n=$ 24); and in the third trimester during cycling (Group 2: mean 16 beats $\min ^{-1}, n=12$ ) and aerobics classes (Group 5: mean 11 beats $\min ^{-1}, n=29$ ). Maximal individual $H R$ under-estimations were large for each physical activity during pregnancy, with values up to 54 beats min $^{-1}$. Consequently, exercise intensity should not be monitored solely with RPE during pregnancy.

Keywords: Pregnancy, exercise, exertion, ratings of perceived exertion, aerobics

The aim of this study was to assess the accuracy of ratings of perceived exertion (RPE) in pregnant women using Borg's $6-20$ point scale as a predictor of the exercise heart rate (HR) in response to several commonly undertaken weight-bearing and nonweight-bearing activities, namely cycling, walking, aerobics and circuit training.

Borg ${ }^{1}$ developed this $6-20$ scale after observing a linear correlation between RPE and HR during cycling in non-pregnant subjects (Table 1). Predicted HR can be calculated from RPE by multiplying RPE by ten ${ }^{1}$. RPE represents the 'integration' ${ }^{1}$ of many exercise related responses including $H R$ and oxygen consumption (absolute and relative values), plasma catecholamine levels, sensations from respiratory effort, elevated muscle and blood lactate levels and muscle fatigue and discomfort ${ }^{1-3}$.

Some authors have advised pregnant women to continue exercising at the same perceived level of exertion as their pre-pregnancy training programmes$^{4}$. However, the recommendation that RPE are useful when prescribing exercise during pregnancy ${ }^{5}$

Address for correspondence: Maureen O'Neill, 62 King St, Doncaster East, Victoria 3109, Australia

(C) 1992 Butterworth-Heinemann Ltd 0306-3674/92/020121-04
Table 1. Borg's 6-20 point scale of ratings of perceived exertion

\begin{aligned} & \hline Rating Perceived exertion \\ & \hline 7 Very, very light \\ & 9 Very light \\ & 11 Fairly light \\ & 13 Somewhat hard \\ & 15 Hard \\ & 17 Very hard \\ & 19 Very, very hard \\ & \hline\end{aligned}

From Borg 1

has been questioned ${ }^{6}$ because the exercise responses of several of the physiological variables that influence RPE are altered during pregnancy ${ }^{6-8}$. Two previous studies in pregnant women observed that RPE were unchanged with moderate intensity cycling ${ }^{9}$ but higher with step-testing at the same target $\mathrm{HR}^{10}$. In view of these conflicting opinions and findings, the applicability of RPE during pregnancy requires further evaluation.

\section{Materials and methods}

Healthy women with uncomplicated singleton pregnancies were tested. Women were classified as 'trained' if they had exercised for 6 weeks or more before the test, at least three times per week for $30 \mathrm{~min}$ or more at an intensity that was high enough to cause perspiration and shortness of breath. 'Sedentary' subjects never participated in exercise sessions and subjects classified as 'neither' exercised once or twice per week or had started or stopped training in the 6 weeks preceding their test. The protocol was approved by the Institutional Ethical Review Committee and all subjects gave informed consent. Questionnaires were filled out during the 30 -min rest period before the test.

Women in Group 1 exercised on a treadmill at 23-28 weeks and 34-37 weeks gestation and again at 8 weeks or more after delivery. The subjects walked continuously for a total of $26 \mathrm{~min}$ - comprising $10 \mathrm{~min}$ 
at $3 \mathrm{~km} \mathrm{~h}^{-1}$ on a $3.5 \%$ slope, $6 \mathrm{~min}$ at $3 \mathrm{~km} \mathrm{~h}^{-1}$ on a $7.0 \%$ slope and $10 \mathrm{~min}$ at $4 \mathrm{~km} \mathrm{~h}^{-1}$ on an $11.2 \%$ slope.

Women in Group 2 exercised on a bicycle ergometer (Monark 370, Sweden) at 34-38 weeks gestation and at 8 weeks or more postpartum. After a 2 min warm-up period, they maintained a constant workload on the upright bicycle for $10 \mathrm{~min}$. The same workloads were repeated after delivery.

RPE were evaluated in Groups 1 and 2 in the last minute of exercise using Borg's 6-20 scale (Table 1). An electrocardiogram (Hewlett Packard 1405A, Blackburn, Australia) (accuracy \pm 1 beat $\min ^{-1}$ ) was used to measure $\mathrm{HR}$ at baseline and in the last minute of exercise.

In further groups, 3, 4 and 5, the Sports Tester PE3000 (Polar Electro, Kempele, Finland) was used to measure $H R$. The average $H R$ readings differ from electrocardiogram $H R$ readings by -0.8 to +3 beats $\min ^{-1}$ (References 11, 12).

In Group 3 the women's response to circuit training was tested between 20 and 28 weeks gestation. After a 2-min warm up using the upright bicycle, each woman exercised for $30-\mathrm{s}$ intervals at work stations comprising cycling, arm work, walking briskly on the spot or leg work. The arm and leg exercises involved isotonic concentric and eccentric contractions at low resistances with frequent (12-15) repetitions using pin-loaded machines. 'Aerobics' music was played in the background. HR was measured every $5 \mathrm{~s}$ and averaged over the last $2 \mathrm{~min}$ of the 30 -min exercise period. RPE were assessed during the last minute of exercise.

The relationship between $H R$ and RPE during aerobics classes was assessed in two different groups - Group 4 subjects were tested at 13-28 weeks gestation and those in Group 5 were tested at 29-39 weeks. The HR was measured every $5 \mathrm{~s}$ and averaged for each song that went for more than $3 \mathrm{~min}$ with a base rhythm of more than 135 beats $\min ^{-1}$ (that is, for each 'cardiovascular track'). At the end of each of these 'tracks', RPE were evaluated. Subjects were also asked to nominate which 'track' was the most intense.

\section{Statistics}

The Minitab statistics package (Release 82.1, Minitab, State College, Pennsylvania) was used and the level of significance was set at $P<0.05$. The predicted HR was calculated by multiplying RPE by ten ${ }^{1}$.

To determine if the subjects in the different groups were similar, one-way analyses of variance were used to compare the demographic data of each group tested at the same stage of gestation or after delivery, in addition to the delivery data.

The influence of pregnancy on the actual HR and predicted HR during exercise in Group 1, and the differences between them, were assessed with repeated measures analysis of variance. NewmanKeul's test was used as a post hoc test.

Paired $t$ tests were used to compare third trimester (T3) and postpartum (PP) values for Group 2.

For each group the actual and predicted HR during pregnancy were compared using paired $t$ tests. The significance of the correlation between HR during exercise and RPE (assessed with Pearson's test) was determined using $z$ values. In Groups 4 and 5, the HR and RPE of the most intense 'track' were used for the comparisons.

\section{Results \\ Demographic and delivery data}

The mean maternal age and height was similar in each group. The mean gestation and weight was similar for groups tested in the second trimester (T2) (Groups 1, 3 and 4), in T3 (Groups 1,2 and 5) and after delivery (Groups 1 and 2) (see Table 2).

All of the babies had 5-min Apgar scores $>7$ and survived the first month after delivery. Two of the women in Group 5 smoked during pregnancy (five and ten cigarettes per day) and had babies with birthweights between the 10th and 25th percentiles. The birthweights of the other babies were between the 25th and 90th percentiles for gestation.

\section{Influence of pregnancy on RPE}

HR during walking and cycling correlated significantly with RPE after delivery (Group 1, $r=0.83, P<$ 0.01 ; Group 2, $r=0.74, P<0.015$ ) but there was no significant correlation when the same subjects were tested in T2 (Group 1, $r=0.45$ ) and/or in T3 (Group 1, $r=0.47$; Group 2, $r=0.51)(P>0.05)$.

RPE and HR also failed to correlate in the pregnant women who participated in aerobics or circuittraining (Group 3, $r=0.39$; Group 4, $r=0.27$; Group $5, r=0.35 ; P>0.05)$.

\section{Influence of pregnancy on predicted $H R$}

Peak HR during treadmill exercise in pregnant women was significantly higher than values obtained after delivery $(P<0.01)$. HR values during exercise were similar in T2 and T3. In contrast, the predicted HR was the same in both trimesters of pregnancy and after delivery. The difference between the exercise and predicted HR was greater in T2 $(P<0.025)$ than T3 and PP (Table 3).

During cycling, a non-weight-bearing exercise, the exercise $\mathrm{HR}$ was the same in T3 and PP. The predicted $H R$ was also similar but there was a non-significant trend for the difference between the actual and predicted HR to be greater during pregnancy.

The predicted HR significantly underestimated the exercise HR in T2 (Group 1, $P<0.015$; Group 3, $P<$ 0.005; Group 4, $P<0.01$ ) and, except when walking, in T3 (Group 2, $P<0.01$; Group 5, $P<0.01$ ). After delivery, the average underestimations of the actual HR by the predicted HR were not significant (Groups 1 and 2).

When asked to pick which 'cardiovascular track' caused the highest HR during an aerobics class, 38 subjects (79\%) were accurate in T2 (Group 4) and 25 $(86 \%)$ were accurate in T3 (Group 5). However, on an individual basis, the greatest underestimations were large, not only with walking (by 48 beats $\mathrm{min}^{-1}$ in T2 and 54 beats min $^{-1}$ in T3), cycling (by 46 beats min $^{-1}$ in T3) and circuit training (by 38 beats $\mathrm{min}^{-1}$ in T2) 
Table 2. Demographic and delivery data

\begin{tabular}{|c|c|c|c|c|c|}
\hline & \multicolumn{5}{|c|}{ Group } \\
\hline & 1 & 2 & 3 & 4 & 5 \\
\hline Number of subjects & 11 & 12 & 24 & 48 & 29 \\
\hline Age (years) & $30(3)$ & $32(4)$ & $30(3)$ & 30(5) & $31(4)$ \\
\hline $\begin{array}{l}\text { Gestation at test (weeks) } \\
\text { T2 } \\
\text { T3 } \\
\text { PP }\end{array}$ & $\begin{array}{l}25(2) \\
35(1) \\
13(3)\end{array}$ & $14(5)$ & $\begin{array}{l}23(2) \\
34(3)\end{array}$ & 23(5) & \\
\hline $\begin{array}{l}\text { Maternal weight }(\mathbf{k g}) \\
\text { T2 } \\
\text { T3 } \\
\text { PP }\end{array}$ & $\begin{array}{l}66(7) \\
70(7) \\
61(8)\end{array}$ & $\begin{array}{l}70(5) \\
60(4)\end{array}$ & $64(6)$ & $65(7)$ & $69(7)$ \\
\hline Height (cm) & 165(6) & $164(6)$ & $166(6)$ & $165(6)$ & $165(6)$ \\
\hline Primiparas:Multiparas & $7: 4$ & $8: 4$ & $16: 8$ & $38: 10$ & 20:9 \\
\hline $\begin{array}{l}\text { Trained: neither: sedentary } \\
\text { T2 } \\
\text { T3 } \\
\text { PP }\end{array}$ & $\begin{array}{l}3: 2: 6 \\
1: 2: 8 \\
3: 0: 8\end{array}$ & $\begin{array}{l}5: 0: 7 \\
2: 4: 6\end{array}$ & $18: 6: 0$ & 44:4:0 & $24: 5: 0$ \\
\hline $\begin{array}{l}\text { Non-smoker: smoker } \\
\text { T2 } \\
\text { T3 } \\
\text { PP }\end{array}$ & $\begin{array}{l}11: 0 \\
11: 0 \\
11: 0\end{array}$ & $\begin{array}{l}10: 2 \\
10: 2\end{array}$ & $23: 1$ & $46: 2$ & $27: 2$ \\
\hline Oral contraceptives postpartum & 1 & 1 & n.a. & n.a. & n.a. \\
\hline Birthweight (kg) & $3.4(0.4)$ & $3.8(0.8)$ & $3.6(0.4)$ & $3.6(0.5)$ & $3.5(0.7)$ \\
\hline Gestation at delivery (days) & $275(12)$ & $277(11)$ & 275(9) & $276(11)$ & 272(13) \\
\hline Sex of baby (male : female) & $6: 5$ & $8: 4$ & $12: 12$ & $22: 26$ & $14: 15$ \\
\hline
\end{tabular}

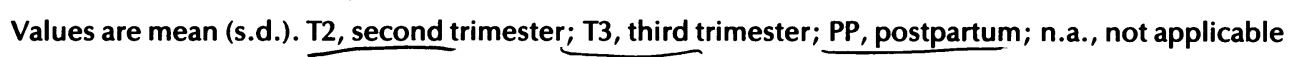

Table 3. Influence of pregnancy on the relationship between exercise heart rates and heart rates predicted from ratings of perceived exertion

\begin{tabular}{|c|c|c|c|}
\hline Group & $T 2$ & $T 3$ & $P P$ \\
\hline $\begin{array}{l}1 \text { (Treadmill) } \\
\text { Exercise HR (beats } \min ^{-1} \text { ) } \\
\text { Predicted HR (beats } \min ^{-1} \text { ) } \\
\text { Difference }\end{array}$ & $\begin{array}{r}143(14) \\
127(20) \\
16(14)\end{array}$ & $\begin{array}{r}141(15) \\
133(20) \\
8(6)\end{array}$ & $\begin{array}{r}129(16) \\
123(21) \\
6(3)\end{array}$ \\
\hline $\begin{array}{l}2 \text { (Cycling) } \\
\text { Exercise HR (beats } \min ^{-1} \text { ) } \\
\text { Predicted HR (beats } \min ^{-1} \text { ) } \\
\text { Difference }\end{array}$ & & $\begin{array}{r}151(18) \\
135(15) \\
16(16)\end{array}$ & $\begin{array}{r}154(22) \\
143(25) \\
11(17)\end{array}$ \\
\hline $\begin{array}{l}3 \text { (Circuit class) } \\
\text { Exercise HR (beats } \min ^{-1} \text { ) } \\
\text { Predicted HR (beats } \min ^{-1} \text { ) } \\
\text { Difference }\end{array}$ & $\begin{array}{r}149(14) \\
131(15) \\
18(17)\end{array}$ & & \\
\hline $\begin{array}{l}4 \text { (Aerobics) } \\
\text { Exercise HR (beats } \min ^{-1} \text { ) } \\
\text { Predicted HR (beats } \min ^{-1} \text { ) } \\
\text { Difference }\end{array}$ & $\begin{array}{r}144(17) \\
129(12) \\
15(15)\end{array}$ & & \\
\hline $\begin{array}{l}5 \text { (Aerobics) } \\
\text { Exercise HR (beats } \min ^{-1} \text { ) } \\
\text { Predicted HR (beats } \min ^{-1} \text { ) } \\
\text { Difference }\end{array}$ & & $\begin{array}{r}143(15) \\
132(15) \\
11(12)\end{array}$ & \\
\hline
\end{tabular}

Values are mean (s.d.) but also during aerobics classes (by 30 beats $\mathrm{min}^{-1}$ in $\mathrm{T} 2$ and 36 beats $\mathrm{min}^{-1}$ in T3).

\section{Discussion}

Several findings suggest that pregnant women should not rely solely on RPE when trying to maintain exercise intensity below target HR such as 140 beats $\min ^{-1}$, as recommended by the American College of Obstetricians and Gynecologists ${ }^{13}$ : first, the correlations between RPE and HR in pregnant women are not significant; second, the predicted HR based on RPE underestimates the actual HR during pregnancy (except for walking in T3). Furthermore, the maximal individual underestimations of the actual by the predicted HR are unacceptably large because some individuals may fail to perceive when exercise intensities are high and this may put the fetus at risk.

The present study was the first to demonstrate that HR predicted from RPE underestimates exercise HR during aerobics, circuit training and walking in pregnant women. Interestingly, the underestimation with walking was greater in T2 than PP. An underestimation was also seen with cycling during 
pregnancy, consistent with the previous findings of Ohtake et al. ${ }^{9}$

The relationship between RPE and HR in pregnant women walking or cycling is not as strong as that observed in the non-pregnant population. This is probably due to a gestational effect rather than to experimental technique because the correlations are significant in the same subjects after delivery. Their PP correlation coefficients are comparable to the range of $0.80-0.90$ found in earlier studies on non-pregnant subjects ${ }^{1}$.

Our observations that RPE during moderate intensity cycling or walking are not influenced by pregnancy confirm the findings of a previous study of non-weight-bearing exercise ${ }^{9}$ but are in conflict with a study of weight-bearing exercise ${ }^{10}$. In the latter study (in which women performed step tests) RPE were found to be higher throughout pregnancy. However, this conclusion was based on comparisons with a non-pregnant control group comprising different subjects, and it was not clear if the intergroup differences were due to pregnancy or to subject selection.

RPE did not change during pregnancy. The effects on RPE of pregnancy-related increases in maternal $\mathrm{HR}$ with weight-bearing exercise ${ }^{7}$, increases in oxygen consumption with weight-bearing and nonweight-bearing exercise ${ }^{8}$ and increases in the ventilatory sensitivity and variability in dyspnoea during exercise $^{6}$ may have been offset by the higher levels of plasma $\beta$-endorphin seen at rest and with exercise in pregnant women ${ }^{14}$.

It was important to compare the responses of RPE and HR to circuit classes with weight-training machines because these classes have been recommended for women with low-risk pregnancies ${ }^{13}$. Each station was worked for $30 \mathrm{~s}$ to duplicate a format commonly used in the community. RPE were not evaluated for each arm or leg exercise separately because RPE should not be assessed until after at least $3 \mathrm{~min}$ of a specific exercise ${ }^{2}$.

With weight-bearing exercise in $\mathrm{T} 3$, the predicted HR underestimated the actual HR during aerobics, but not when walking without background music. This finding may be due to the motivating effects of the music: when non-pregnant women exercise at low or moderate intensity, the addition of background music lowers RPE even though HR remains the same ${ }^{15}$. In addition, most pregnant women who were tested during aerobics classes were in training, whereas those who were tested on a treadmill were generally sedentary. 'Trained' women may be at greater risk of underestimating exercise intensity when using RPE during gestation than sedentary women. RPE are lower in trained than in untrained non-pregnant runners at $50,60,70$ and $80 \%$ of maximal oxygen consumption ${ }^{3}$. Similarly, when training occurs during pregnancy, RPE decreases out of proportion to the decrease in HR at a given workload ${ }^{9}$. Wallace and Engstrom ${ }^{4}$ cautioned pregnant women that "The advice, "listen to your body" may not be adequate in athletes because they are used to ignoring symptoms of pain'.

In conclusion, pregnant women may capitalize on their ability to perceive which aerobics 'tracks' are intense by taking more frequent pulse checks during such tracks. However, unless a pregnant woman has had simultaneous feedback about her RPE and HR during exercise and can accurately match her RPE to the actual HR, she should monitor her HR throughout exercise and not wait until she perceives the exercise as being intense.

\section{Acknowledgements}

The authors wish to thank Associate Professor Barry McGrath of Prince Henry's Hospital in Melbourne for his constructive comments and the following Fitness Centres for their participation: Les Mills' World of Fitness, Auckland; 1812, Sydney; Aerobic City, Sydney and Just Aerobics, Melbourne, Australia.

\section{References}

1 Borg GAV. Psychophysical bases of perceived exertion. Med Sci Sports Exerc 1982; 14: 377-81.

2 Birk TJ, Birk CA. Use of ratings of perceived exertion for exercise prescription. Sports Med 1987; 4: 1-8.

3 Demello JJ, Cureton KJ, Boineau RE, Singh MM. Ratings of perceived exertion at the lactate threshold in trained and untrained men and women. Med Sci Sports Exerc 1987; 19: 354-62.

4 Wallace AM, Engstrom JL. The effects of aerobic exercise on the pregnant woman, fetus and pregnancy outcome: a review. I Nurse Midwifery 1987; 32: 277-90.

5 American College of Sports Medicine. Guidelines for graded exercise testing and prescription, 3rd ed. Philadelphia: Lea and Febiger, 1986: 82-3.

6 Wolfe LA, Ohtake PJ, Mottola MF, McGrath MJ. Physiological interactions between pregnancy and aerobic exercise. Exerc Sport Sci Rev 1989; 17: 295-351.

7 Cooper KA, Hunyor SN, Boyce ES, O'Neill ME, Frewin DB. Fetal heart rate and maternal cardiovascular and catecholamine responses to dynamic exercise. Aust $N \mathrm{Z} J$ Obstet Gynaecol 1987; 27: 220-3.

8 Carpenter MW, Sady SP, Sady MAet al. Effect of maternal weight gain during pregnancy on exercise performance. $J$ Appl Physiol 1990; 68: 1173-6.

9 Ohtake PJ, Wolfe LA, Hall P, McGrath MJ. Physical conditioning effects on exercise heart rate and perception of exertion in pregnancy. Can J Sport Sci 1988; 13: 71P-73P.

10 Williams A, Reilly T, Campbell I, Sutherst J. Investigation of changes in responses to exercise and in mood during pregnancy. Ergonomics 1988; 31: 1539-49.

11 Macfarlane D, Fogarty B, Hopkins W. The accuracy and variability of commercially available heart rate monitors. $N Z J$ Sports Med 1989; 17: 51-3.

12 Karvonen J, Cwalbinska-Moneta J, Saynajakan-Gas S. Comparison of heart rates measured by ECG and microcomputer. Phys Sportsmed 1984; 12: 65-9.

13 American College of Obstetricians and Gynecologists. Home exercise program: exercise during pregnancy and the postnatal period. Washington DC, USA: American College of Obstetricians and Gynecologists, 1985.

14 Rauramo I, Salminen K, Laatikainen T. Release of betaendorphin in response to physical exercise in non-pregnant and pregnant women. Acta Obstet Gynecol Scand 1986; 65: 609-12.

15 Boutcher SH, Trenske M. The effects of sensory deprivation and music on perceived exertion and effect during exercise. $J$ Sports Exerc Psychol 1990; 12: 167-76. 